\title{
Peran Perawat Dalam Mempertahankan Posisi Ergonomik Pasien Di Rumah Sakit
}

\author{
Putri Meiyarny Zega
}

putrimeiyarny@gmail.com

\section{LATAR BELAKANG}

Dari waktu ke waktu keberadaan institusi rumah sakit semakin dituntut untuk memberikan pelayanan prima dalam bidang kesehatan kepada masyarakat. Kebutuhan ini sejalan dengan dua hal penting, yaitu semakin ketatnya kompetisi sektor rumah sakit dan seiring dengan peningkatan kesadaran serta tuntutan pasien terhadap kualitas pelayanan rumah sakit. Rumah sakit merupakan institusi pelayanan kesehatan yang menyelenggarakan pelayanan kesehatan perorangan secara paripurna yang menyediakan pelayanan rawat inap, rawat jalan dan gawat darurat.

Dalam pelayanan kesehatan, para perawat diharapkan juga dapat memberikan pelayanan secara berkualitas. Perawat sebagai tenaga kesehatan yang profesional dan merupakan tenaga kesehatan terbesar yang ada di rumah sakit mempunyai peranan yang sangat penting dalam mewujudkan keselamatan pasien. Perawat berperan mencegah dalam kesalahan medis, mencegah perawatan yang dapat merugikan kesehatan dan menekankan pada pelaporan kejadian yang dapat merugikan pasien. Untuk menjaga patient safety salah satunya dengan menjaga kompetensi perawat yang melakukan tindakan keperawatan mempertahankan posisi ergonomik pasien.

Ergonomi berasal dari kata yunani yaitu ergo yang berarti kerja dan nomos yang berarti hukum. Dengan demikian ergonomi dimaksudkan sebagai disiplin keilmuan yang mempelajari manusia dalam kaitannya dengan pekerjaan. Disiplin ergonomi secara khusus mempelajari keterbatasan dari kemampuan manusia dalam berinteraksi dengan teknologi dan produkproduk buatannya. Disiplin ini berangkat dari kenyataan bahwa manusia memiliki batas-batas kemampuan, baik jangka pendek maupun jangka panjang, pada saat berhadapan dengan keadaan lingkungan sistem kerjanya yang berupa perangkat keras/hardware (mesin, peralatan kerja, dan lainlain) dan/atau perangkat lunak/software (metode kerja, sistem dan prosedur, dan lainlain). Dengan demikian, ergonomi adalah suatu keilmuan yang multi disiplin, karena 
mempelajari pengetahuan-pengetahuan dari ilmu kehayatan (kedokteran, biologi), ilmu kejiwaan (psychology) dan kemasyarakatan (sosiologi).

\section{METODE}

Artikel ilmiah ini dibuat dengan menggunakan metode literasi/membaca dan menganalisa kajian dari berbagai sumber atau referensi terkait seperti jurnal, buku teks, dan Ebook 8 tahun terakhir. Artikel ilmiah ini ditulis dengan mengacu pada sumber-sumber terkait yang berfokus pada penyakit akibat kerja di rumah sakit.

\section{HASIL}

Hasil analisa yang di dapatkan adalah ergonomi adalah ilmu, teknologi dan seni yang berupaya menserasikan alat, cara kerja dan lingkungan kerja terhadap kemampuan, kebolehan dan batasan manusia untuk mewujudkan kondisi lingkungan kerja yang sehat, aman, nyaman dan efisien sehingga tercapai produktivitas yang setingi-tinginya.

Ergonomi adalah applied science yang kajiannya pada designing dan arranging benda yang digunakan manusia sehingga memungkinkan adanya interaksi yang efisien dan aman dan bukan sebaliknya. Ergonomi bukan hanya sekedar mencegah gangguan pada otot dan kerangka tetapi ergonomi juga sangat penting dalam mencegah penyakit dan kelainan tubuh. Ergonomi memperhatikan berbagai aspek yaitu range of motion dan mekanika tubuh (berbaring; duduk; berdiri; mengangkat serta berjalan) yang dapat berdampak pada gangguan kenyamanan kerja, kelelahan, kelainan otot dan kerangka. Oleh karena itu, sudah jelas bahwa penting sekali bagi pasien mengetahui apa itu kondisi ergonomik yang benar dan yang seharusnya dilakukan oleh pasien demi menjangkau keselamatannya.

Adapun tujuan penerapan ergonomik adalah sebagai berikut :

1. Meningkatkan kesejahteraan fisik dan mental dengan meniadakan beban kerja tambahan(fisik dan mental), mencegah penyakit akibat kerja, dan meningkatkan kepuasan kerja.

2. Meningkatkan kesejahteraan social dengan jalan meningkatkan kualitas kontak sesame pekerja, pengorganisasian yang lebih baik dan menghidupkan system kebersamaan dalam tempat kerja.

3. Berkontribusi di dalam keseimbangan rasional antara aspek-aspek teknik, ekonomi, antropologi dan budaya dari sistem manusia-mesin untuk tujuan meningkatkan efisiensi sistem manusia-mesin. 


\section{PEMBAHASAN}

Istilah ergonomic berasal dari bahasa latin yaitu ergon (kerja) dan nomos (hukum alam) dan dapat didefinisikan sebagai studi tentang aspek-aspek manusia dalam lingkungan kerjanya, dan ditinjau secara anatomi, fisiologi, psikologi, engineering, manajemen dan desain atau perancangan. Ergonomic berkenaan pula dengan optimasi, efisiensi, kesehatan, keselamatan dan kenyamanan manusia di tempat kerja, di rumah, dan di tempat rekreasi. Ergonomic adalah penerapan ilmu biologis tentang manusia bersama-sama dengan ilmu-ilmu teknik dan teknologi. Untuk mencapai penyesuaian satu sama lain secara optimal dari manusia terhadap pekerjaannya, yang manfaatnya diukur dengan efisiensi dan kesejahteraan kerja.

Ergonomic merupakan ilmu yang penerapannya berusaha untuk menyerasikan pekerjaan dan lingkungan terhadap orang atau sebaliknya, dengan tujuan tercapainya produktivitas dan efisiensi setinggi-tingginya melalui pemanfaatan factor manusia seoptimal mungkin. Ergonomic merupakan pertemuan dari berbagai ilmu seperti antropologi, biometrika, faal kerja, hygiene perusahaan dan kesehatan kerja, perencanaan kerja dan cybernetrica, namun kekhususan utamanya adalah perencanaan dari cara bekerja yang lebih baik meliputi tata kerja dan peralatannya.

Disamping itu ergonomi juga memberikan peranan penting dalam meningkatkan faktor keselamatan dan kesehatan kerja. Misalnya : desain suatu sistem kerja untuk mengurangi rasa nyeri dan ngilu pada sistem kerangka otot manusia, desain stasiun kerja untuk alat peraga visual. Hal itu adalah untuk mengurangi ketidaknyamanan visual dan postur kerja, desain suatu perkakas kerja untuk mengurangi kelelahan kerja.

Dalam mempertahankan keselamatan pasien, perawat harus mempertahankan posisi ergonomik pada pasien, antara lain :

\section{Berdiri}

a. Berdiri seimbang ditandai dengan :

garis vertikal berada dalam bidang tumpuan

gaya pada masing-masing sendi $=0$

keseimbangan tergantung pada tinggi pusat gaya berat \& besarnya bidang tumpuan

b. Ada dua macam berdiri

simetris : kedua tungkai bebannya sama

asimetris : kedua tungkai beban tidak sama

c. Jika berdiri tegang, paling efisien dalam hal 
berubah posisi

kebutuhan energinya peling sedikit, kadang-kadang $=$ BMR

d. Centre of gravity saat berdiri tegak, sedikit dibawah pusar

2. Berjalan

Cara berjalan yang baik adalah :

a. Biasakan berjalan dengan tubuh yang tegak. Membiasakan berjalan dengan punggung tegak dan mengangkat dagu agar sejajar dengan lantai. Dengan menjaga postur ini selama berjalan, Anda bisa bernapas lebih leluasa sebab tulang punggung Anda tetap lurus sehingga tidak menekan diafragma. Jangan berjalan sambil menunduk atau membungkuk sebab postur tubuh yang buruk lambat laun membuat punggung terasa nyeri, leher kaku, dan bahkan muncul keluhan lain yang lebih serius.

b. Biasakan melangkah dengan gerakan menggulung telapak kaki, yaitu mengangkat telapak kaki dimulai dari tumit sampai ke jari-jari kaki dengan arah lurus ke depan. Cara ini akan mengaktifkan otot betis sehingga telapak kaki membentuk sudut yang tepat saat terangkat dari lantai setiap kali Anda melangkah.

c. Tariklah kedua bahu sedikit ke belakang, tetapi biarkan tetap rileks. Saat berjalan, Anda akan lebih banyak mengandalkan otot kaki dan otot perut.

d. Ayunkan lengan selama Anda berjalan. Mengayunkan lengan adalah hal biasa bagi banyak orang. Biarkan kedua lengan tergantung ke bawah secara alami. Saat mulai berjalan, lengan Anda akan berayun sedikit.

3. Duduk

Pekerjaan sejauh mungkin harus dilakukan sambil duduk, begitu pula pasien. Duduk memerlukan sedikit energy daripada berdiri, karena hal itu mengurangi banyaknya beban otot kaki. Posisi yang baik adalah :

a. Fleksi lutut : 90 derajat

b. Fleksi badan - paha : 90 derajat

c. Rotasi ke belakang pelvis lebih besar atau sama dengan 30 derajad

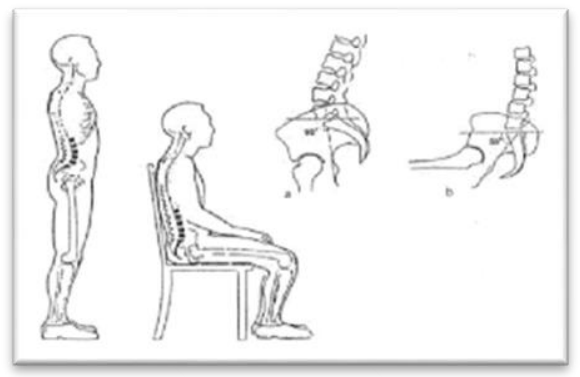


Pada saat duduk terjadi hal-hal

a. terjadi deformitas discus inter vertebralis

b. terjadi peningkatan ketegangan pada annulus

c. terjadi peningkatan ketegangan pd nukleus.

d. Anderson ('74), tekanan intra discus meningkat 40\% dari pada berdiri.

e. Tekanan pada discus $=$ tekanan osmotik nukleus.

f. Peningkatan tekanan pada diskus karena proses dehidrasi.

g. Penurunan tekanan pada diskus saat rehidrasi diskus.

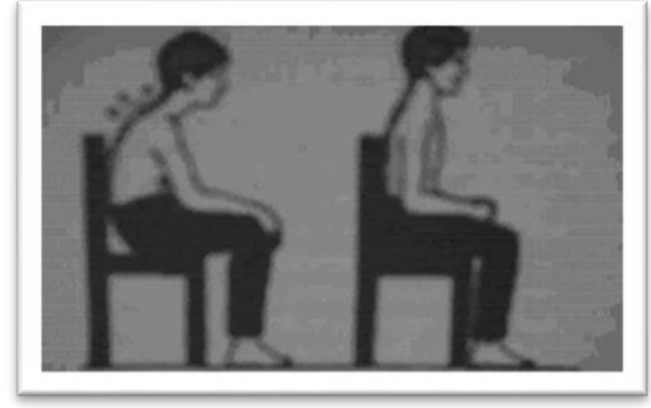

Tekanan intra diskus dipengaruhi oleh :

a. Berat tubuh bagian atas

b. Deformasi bagian diskus

c. Ketegangan otot bagian belakang

Sikap duduk yang keliru merupakan penyebab adanya masalah-masalah punggung. Operator dengan sikap duduk yang salah akan menderita pada bagian punggungnya. Tekanan pada bagian tulang belakang akan meningkat pada saat duduk, dibandingkan pada saat berdiri ataupun berbaring. Sikap duduk yang tegang lebih banyak memerlukan aktivitas otot atau urat syaraf belakang daripada sikap duduk yang condong ke depan.

Selain akibat diatas, bekerja sambil duduk dapat menyebabkan :

a. Melembeknya otot perut

b. Melengkungnya punggung

c. Tidak baik bagi alat-alat dalam, khususnya peralatan pencernaan jika posisi duduk dilakukan secara membungkuk

d. Keluhan sakit pada punggung bagian bawah (law back pain)

4. Berbaring

a. Dorsal RACKBIKE (tergeletak di belakang), rawan (berbaring pada perut)

b. Sims (semi-rawan-berbaring di samping [biasanya kiri] dengan atas lutut tertekuk) 
c. Fowler di (tergeletak di belakang, dengan kepala tinggi), lutut-dada atau genupectoral (berbaring di lutut, dengan dada beristirahat di tempat tidur)

d. Dorsal lithotomy (tergeletak di belakang, dengan kaki di sanggurdi), dan lateral (berbaring di samping). Posisi telentang dapat dimodifikasi dengan menekuk lutut dan menempatkan kaki datar di tempat tidur.

e. Trendelenburg's (posisi kepala-down berbaring dengan kepala lebih rendah dari kaki)digunakan untuk mengobati sengatan, dengan mempromosikan aliran darah ke otak.

\section{Jongkok}

Posisi : lutut fleksi max, paha, badan fleksi max dan lumbal juga fleksi max. Menurut HR Farnil ('75) menyatakan jongkok lebih baik, karena :

a. Mencegah lordosis

b. Orang Afrika \& Oriental yang lebih banyak jongkok dalam melakukan aktivitasnya, terhindar dari sakit pinggang

c. Dapat membantu pengosongan usus besar

Prinsip kerja secara Ergonomis, agar terhindar dari cedera :

1. Gunakan tenaga seefisien mungkin, beban yang tidak perlu harus dukurangi/dihilangkan, perhitungkan gaya berat yang mengacu pada berat badan dan bila perlu gunakan pengungkit sebagai alat bantu.

2. Sikap tubuh berdiri, duduk dan jongkok hendaknya disesuaikan dengan prinsip-prinsip ergonomi.

3. Panca indera dapat dimanfaatkan sebagai alat kontrol, bila payah harus istirahat (jangan dipaksa) dan bla lapar/haus harus makan/minum (jangan ditahan).

4. Jantung digunakan sebagai parameter yang diukur lebih dari jumlah maksimal yang diperbolehkan.

\section{PENUTUP}

\section{Kesimpulan}

Ergonomi adalah studi untuk menciptakan sistem kerja manusia yang lebih sehat, aman, dan nyaman. Dalam menerapkan keselamatan pasien, perawat harus dapat mempertahakan posisi ergomik. Ergonomik bukan hanya sekedar mencegah gangguan pada otot dan kerangka tetapi ergonomi juga sangat penting dalam mencegah penyakit dan kelainan tubuh. Ergonomi memperhatikan berbagai aspek yaitu range of motion dan mekanika tubuh (berbaring; duduk; berdiri; mengangkat serta berjalan) yang dapat berdampak pada gangguan kenyamanan kerja, kelelahan, kelainan otot dan kerangka pada pasien. 
Dalam mempertahankan keselamatan pasien, perawat harus mempertahankan posisi ergonomik pada pasien, antara lain :
1) Posisi Berdiri,
2) Posisi Berjalan,
3) Posisi Duduk,
4) Posisi Berbarinng, dan
5) Posisi Jongkok.

2. Saran

Sebagai seorang perawat ataupun mahasiswa keperawatan dapat berkerja profesional dalam menjalankan tugas dan kewajiban sebagai seorang perawat yang ideal dan bertanggung jawab. Dalam asuhan keperawatan, seorang perawat wajib mengetahui keselamatan pasien, salah satunya dengan menerapkan posisi ergonomik pada pasien.

\section{DAFTAR PUSTAKA}

Azza Ivana, B. W. (2014). Analisa Komitmen Manajemen Rumah Sakit (RS) Terhadap Keselamatan Dan Kesehatan Kerja (K3) Pada RS Prima Medika Pemalang. Jurnal Kesehatan Masyarakat, 2(1), 35-41.

Balaputra, Ishana, dan Adi Heru Sutomo. (2017). Pengetahuan Ergonomi Dan Postur Kerja Perawat Pada Perawatan Luka Dengan Gangguan Muskuloskeletal Di Dr. H. Koesnadi Bondowoso. Berita Kedokteran Masyarakat (BKM Journal of Community Medicine and Public Health), 33(9), 445-448.

Fathi, A., \& Simamora, R. H. (2019, March). Investigating nurses' coping strategies in their workplace as an indicator of quality of nurses' life in Indonesia: a preliminary study. In IOP conference series: Earth and Environmental science (Vol. 248, No. 1, p. 012031). IOP Publishing.

K., Ni Guru, Putu Oka. (2018). Kajian Ergonomi Pada Tindakan Keperawatan di IRD RS Universitas Udayana, Badung, Bali. Jurnal Keperawatan Respati Yogyakarta, 5(3), 414419.

Kumala, Tria Firza, dan Meihastini. (2018). Efektifitas Ergonomik Exercise Terhadap Hiperurisemia. Prosiding Pertemuan Ilmiah Nasional Penelitian \& Pengabdian Masyarakat (PINLITAMAS 1), 1(1), 132-140. 
Neffrety Nilamsari, S. S. (2015). Prototype Bangku Ergonomis Untuk Memperbaiki Posisi Duduk. Jurnal Ners , 10(1), 87-103.

Prapti, Ni Ketut, Guru, Putu, Oka, Yuli, Nurhesti , \& Ketut, Tirtayasa. (2018).Kajian Ergonomi pada Tindakan Keperawatan di IRD RS UNIVERSITAS UDAYANA, BADUNG, BALI. Jurnal Keperawatan Respati Yogyakarta, 5(3), 414-419.

Purnama, Ign., Luddy,Indra, Purnama, Luciana, Triani, Dewi,\& Deny, Ratna, Yuniartha. (2015). lmplementasi Desain Fasilitas Kerja Ergonomis untuk Menurunkan Resiko pada Postur Kerja Duduk Statis. Jurnal Rekayasa Sistem Industri, .4(1).

Simamora, R. H. (2020). Learning of Patient Identification in Patient Safety Programs Through Clinical Preceptor Models. Medico Legal Update, 20(3), 553-556.

Tarwaka. (2012). Dasar-dasar Pengetahuan Ergonomi dan Ini Aplikasi di Tempat Kerja. Surakarta: Harapan Press.

Triwibowo, Cecep, dan S. Y. (2016). Handover Sebagai Upaya Peningkatan Keselamatan Pasien. Jurnal Keperawatan Soedirman, 11(2), 76-80

Yuwono, Rio, dan Ferida Yuamita. (2015). Analisa Faktor K3 Dan Ergonomi Terhadap Fasilitas Pusat Kesehatan Universitas Untuk Mengukur Kepuasan Pasien. Jurnal Ilmiah Teknik Industri, 14(1), 1-12. 